Article publié par le Laboratoire de Construction en Béton de l'EPFL

Paper published by the Structural Concrete Laboratory of EPFL

\begin{tabular}{|l|l|}
\hline Title: & $\begin{array}{l}\text { Size effect in shear and punching shear failures of concrete members without } \\
\text { transverse reinforcement: Differences between statically determinate members } \\
\text { and redundant structures }\end{array}$ \\
\hline Authors: & Fernández Ruiz M., Muttoni A. \\
\hline Published in: & Structural concrete \\
\hline DOI & $10.1002 /$ suco.201700059 \\
\hline Pages: & pp. $1-11$ \\
\hline Year of publication: & 2017 \\
\hline Type of publication: & Peer reviewed journal article \\
\hline
\end{tabular}

Please quote as:

Fernández Ruiz M., Muttoni A., Size effect in shear and punching shear failures of concrete members without transverse reinforcement: Differences between statically determinate members and redundant structures, Structural concrete, 2017, pp. 1-11. 


\title{
Size effect in shear and punching shear failures of concrete members without transverse reinforcement: Differences between statically determinate members and redundant structures
}

\author{
Miguel Fernández Ruiz ํㅣ | Aurelio Muttoni
}

École Polytechnique Fédérale de Lausanne, Lausanne, Switzerland

\section{Correspondence}

Miguel Fernández Ruiz, École Polytechnique Fédérale de Lausanne, School of Architecture, Civil and Environmental Engineering (ENAC), Station 18, CH-1015 Lausanne, Switzerland Email: miguel.fernandezruiz@epfl.ch

Funding information

Swiss Federal Road Administration, Grant/Award number: AGB 2011-015
Large efforts have been devoted in the past to understanding size effect in shear failures of members without transverse reinforcement. Experimental works have demonstrated that increasing the size reduces the nominal shear strength provided that the failure mode is brittle. For large specimen sizes where a linear behavior can be assumed between the opening of the shear cracks and the acting shear force, the size effect agrees with linear-elastic fracture mechanics (LEFM). In this case, the reduction of nominal shear strength is characterized with respect to the specimen size by an asymptotic slope (in double-log scale) of $-1 / 2$. However, such a linear relationship between crack widths and applied shear force is not present in most reinforced concrete structures, where the response is characterized by a nonlinear behavior at a cracked stage. In these cases, the influence of size effect shall be milder, and the slope (in double-log scale) characterizing it shall be lower than $-1 / 2$. In this paper, the influence of size effect on structures characterized by internal redundancy (continuous one-way members and slabs in case of punching shear with a nonlinear response) is investigated in the frame of the critical shear crack theory. The theory predicts the same influence as LEFM with respect to size effect when a linear behavior can be assumed, but it yields consistently milder influence of size effect for structurally redundant elements with a nonlinear response.

\section{KEYWORDS}

concrete structures, critical shear crack theory, punching shear strength, shear strength, size effect

\section{1 | INTRODUCTION}

The influence of size effect in shear and punching shear failures has been a controversial topic of research in the last decades. Although its influence has been acknowledged experimentally and theoretically, its significance and implications for design do not yet find a consensus. For instance, with respect to shear design in codes, some do not account for this phenomenon (as ACI 318-14 ${ }^{1}$ ), others propose empirical factors (as Eurocode $2^{2}$ ) and some calculate it on the basis of mechanical models (as MC2010 ${ }^{3}$ ).
For cracked beams failing in shear, a large number of tests has been performed in the past with varying sizes (typically from $10 \mathrm{~cm}$ up to $4.0 \mathrm{~m}^{4}$ ). The majority of these tests correspond to simply supported beams subjected to concentrated loads (under three- or four-point bending conditions, refer to Figure 1a). The results of these tests have shown that the influence of size effect is variable, with almost negligible influence when a strength or yield criterion governs (typically associated to low member sizes), but quite significant in case of a sudden and brittle crack propagation (typically associated with large member sizes). ${ }^{4}$ For brittle 
(a)

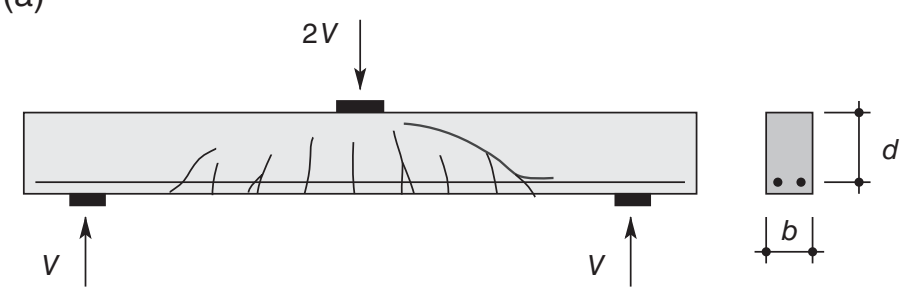

(c)

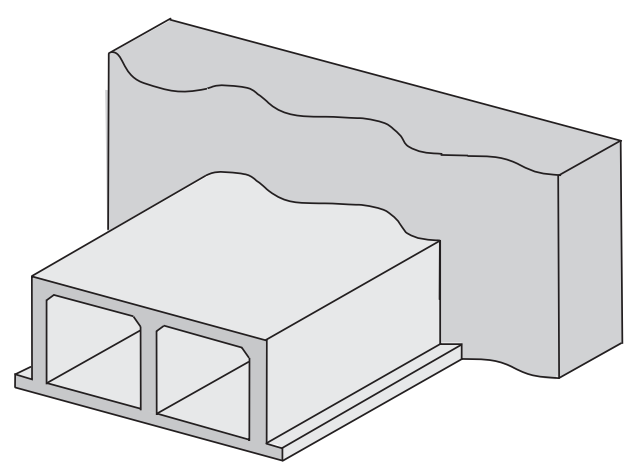

(b)

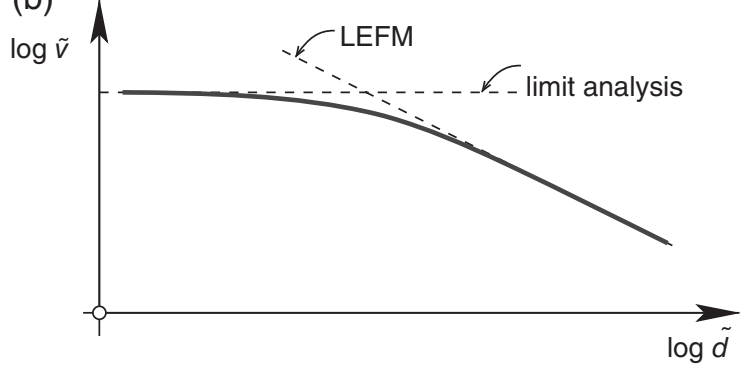

(d)

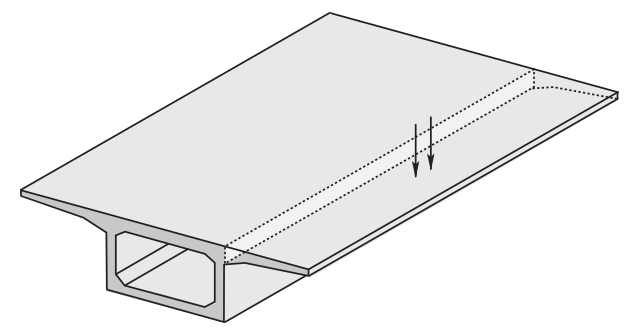

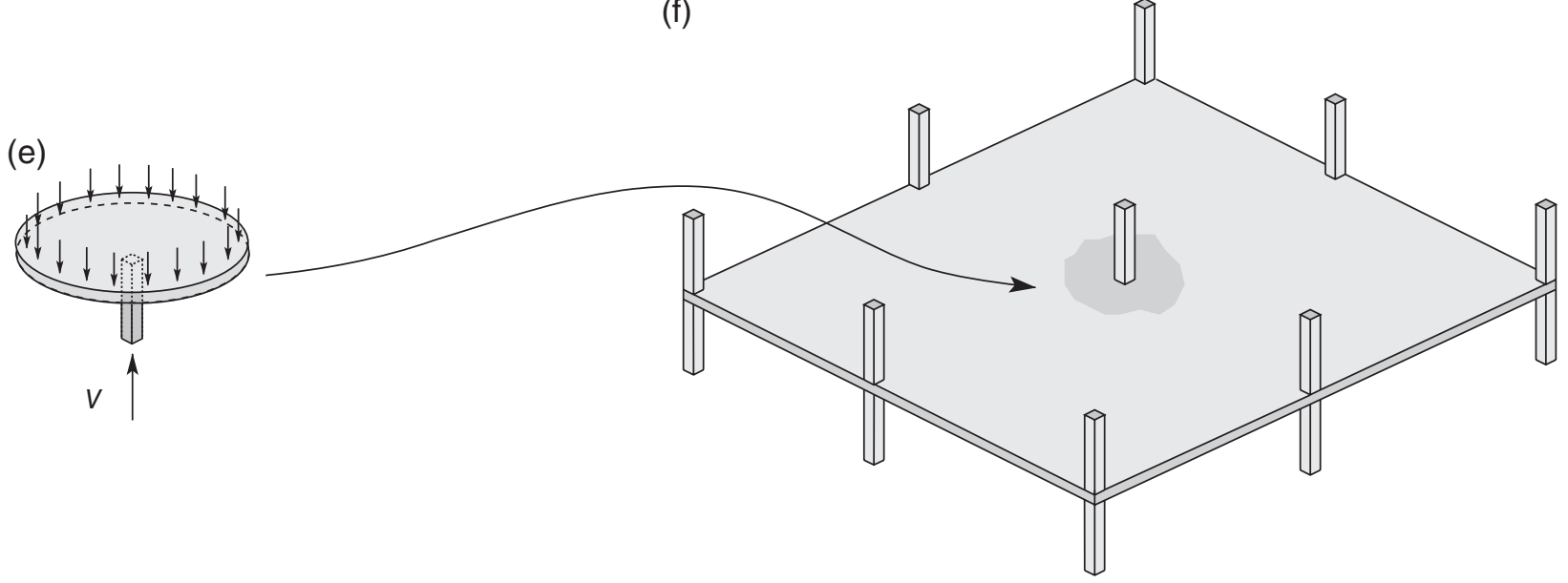

FIGURE 1 Shear and punching shear failures: (a) classical academic (statically determinate) beam shear test; (b) corresponding size-effect law;

(c) redundant structure in the transversal direction (cut-and-cover tunnel); (d) redundant structure in the longitudinal direction (bridge deck slab); (e) slab sector; and (f) continuous flat slab

failures with significant size-effect influence, the behavior of test specimens is reasonably well approximated by assuming a linear relationship between the acting (shear) force and the crack widths (see Reference 5 experimental evidence will be discussed in this paper). By using linearelastic fracture mechanics (LEFM), the influence of size effect on the strength of asymptotically large specimens can be calculated, ${ }^{6}$ corresponding to a slope (in double-log scale) of $-1 / 2$, refer to Figure $1 b$ (plotted for normalized values for the size and shear strength parameters, values for such normalization will be introduced in the next section). The transition between the two regimes (controlled by a yield criterion or controlled by LEFM) can be characterized by a smooth curve that is normally referred to as the size- effect law (according to Bažant et $\mathrm{al}^{6}$ ). The validity of this slope for statically determinate members can also be demonstrated by other means as for instance the critical shear crack theory ( $\mathrm{CSCT},{ }^{5}$ a consistent study on this topic can be referred elsewhere ${ }^{7}$ ).

As it will be shown in this paper, the observed size effect for statically determinate beams is not necessarily representative of actual members failing in shear without transverse reinforcement. These are mostly slabs, with the capacity to act as two-way members and in many cases with a redundant static system, refer to Figure 1c,d. For these members, redistribution of internal forces occur after cracking and reinforcement yielding, and the linearity between acting shear forces and crack widths can be 
considered as no longer applicable (neither the size effect influence predicted by LEFM). Theoretically, the slope shall be milder, with an influence depending on the deviation with respect to a linear behavior. Despite this fact, the influence of size effect on shear design formulas has been adapted in several cases from that of statically determinate members.

For punching shear failures, the influence of the nonlinear response on the size effect is even more significant as two-way slabs are internally redundant members with significant internal force redistributions (in radial and tangential directions and between hogging and sagging regions, ${ }^{8}$ Figure 1f) and where the effects of tension stiffening are very marked. ${ }^{9}$ Even for slab sectors (Figure 1e), the response (shear force-crack width) is notably nonlinear due to these aspects (tension-stiffening and radialtangential moment redistribution due to cracking and yielding ${ }^{9}$ ).

Previous investigations based on analysis of experimental results have already shown that the asymptotic slope for size effect in punching failures governed by brittle failures is milder than $-1 / 2$ (expressed in double-log scale), indicating that the behavior deviates from that of LEFM. ${ }^{10}$ This phenomenon can be demonstrated theoretically by using the $\mathrm{CSCT}^{9,11}$ (ground of current MC2010 punching provisions ${ }^{12,13}$ ), which yields an influence of size effect on the punching strength governed by a slope closer to $-1 / 3 .{ }^{14}$ This value is also in agreement to other theoretical approaches for punching shear. ${ }^{15}$

This paper reviews these aspects by identifying and justifying based on experimental evidence the cases where the behavior of brittle failures in shear can be approximated by LEFM and the cases where the actual behavior deviates from it. Based on the theoretical frame of the CSCT, suitable values for the influence of size effect are derived in terms of the slope describing brittle failures (expressed in double-log scale). On that basis, recommendations are provided for design.

\section{I SIZE EFFECT IN SHEAR FAILURES OF ONE-WAY SLABS WITHOUT TRANSVERSE REINFORCEMENT}

The influence of size effect on the shear strength of oneway slabs and beams without transverse reinforcement is investigated in this section both for statically determinate (as for instance simply supported beams, as usually tested in laboratory) and redundant members (as continuous oneway members, which are more representative of practical cases). The aim of this section is to highlight their differences and expected consequences with reference to size effect. To that purpose, the theoretical frame of the CSCT is used to analyze the shear strength and to perform the comparisons.

\subsection{The capacity of cracked concrete to transfer shear forces}

According to the CSCT, the capacity of cracked concrete to transfer shear forces is characterized by a failure criterion accounting for the various potential shear-transfer actions ${ }^{7}$ (namely aggregate interlock, residual tensile strength of concrete, dowelling action, and inclination of compression chord). The failure criterion results from integration of the stresses developed at the critical shear crack accounting for its shape and kinematics at failure. It can be demonstrated in References 5,7 that the shear failure criterion is in fact dependent on the opening $(w)$ and roughness of the critical shear crack leading to failure. In addition, it can be demonstrated that the capacity of cracked concrete to transfer shear forces decreases for increasing crack openings or decreasing crack roughness.

For practical purposes, the failure criterion can be defined by a single function where it is assumed that the critical shear crack width is proportional to a reference strain times the effective depth of the member $\left(w \propto \varepsilon \cdot d^{5}\right)$ leading to the following failure criterion:

$$
\frac{V_{R}}{b \cdot d \sqrt{f_{c}}}=\frac{1}{3} \cdot \frac{1}{1+120 \frac{\varepsilon \cdot d}{d_{d g}}} \text { (SI units [MPa, mm]), }
$$

where $b$ refers to the width of the member, $d$ to its effective depth, $f_{c}$ to the compressive strength of concrete measured in cylinder, and $d_{d g}$ to the equivalent crack roughness $\left(d_{d g}=d_{g}+16 \mathrm{~mm} \leq 40 \mathrm{~mm}\right.$, where $d_{g}$ refers to the maximum aggregate size). With respect to the reference strain $(\varepsilon)$, it is considered at a distance equal to $0.6 d$ of the compression face and at $d / 2$ of the applied load (location of the control section, extended considerations can be consulted elsewhere ${ }^{5}$. It can be noted that in the previous expression, the crack width accounts both for the size $(d)$ and for the strain of the member $(\varepsilon)$, thus coupling both phenomena.

\section{2 | Statically determinate members-Size effect in shear for a linear structural response}

The shear strength and the influence of size in statically determinate members (for instance simply supported beams and one-way slabs) has been previously investigated in detail by means of the CSCT. ${ }^{7}$ The strength can be calculated by intersecting the failure criterion by the law describing the relationship between the acting shear force at the control section and the associated crack openings.

For statically determinate members, it can be accepted that the reference strain $(\varepsilon)$ and thus the opening of the cracks $(w)$ are linearly dependent on the acting bending moment. ${ }^{5}$ This assumption is grounded on the reduction and eventual loss of reinforcement-to-concrete bond stresses due to the development of horizontal or inclined cracks at the level of the reinforcement ${ }^{7}$ limiting the tension-stiffening effects. The development of these cracks (eventually leading to a 
delamination crack) is investigated in detail by Cavagnis et $\mathrm{al}^{16}$ (named as type "D" cracks). This fact is shown in Figure 2 showing the results of a specimen (SC70) tested and instrumented consistently with the results presented in Reference 16. In that figure, the horizontal opening of the crack at point " $\mathrm{A}$ " is investigated. This point is located at the same depth as that considered by the CSCT as a reference fiber (where flexural cracks have already merged). Figure $2 b-d$ shows the evolution of the crack pattern as well as of the horizontal opening of the crack. At early cracking stages (Figure 2b), the behavior is not linear with a rapid increase of the crack opening. Thereafter (Figure 2c), the relationship between the crack widths and the acting shear force is rather linear (with proportional increases for both). This behavior continues up to near failure (Figure 2d) when, in the last load increments (Figure 2e), the linearity is again lost.
On the basis of these considerations, a linear elastic cracked behavior can be reasonably assumed. In this case, for the depth of the reference fiber, the strains can be approximated by the following expression (neglecting tension-stiffening effects in the sectional analysis, Figure 3):

$$
\varepsilon=\frac{M}{\rho \cdot b \cdot d \cdot E_{s}(d-c / 3)} \frac{0.6 d-c}{d-c} .
$$

For a simply supported beam subjected to a concentrated load, the bending moment at the control section (located at $d / 2$ from the load, see Figure $3 b$ ) results $M=V_{R}(a-d / 2)$ so that:

$$
\varepsilon=\frac{V_{R}(a-d / 2)}{\rho \cdot b \cdot d \cdot E_{s}(d-c / 3)} \frac{0.6 d-c}{d-c},
$$

(a)

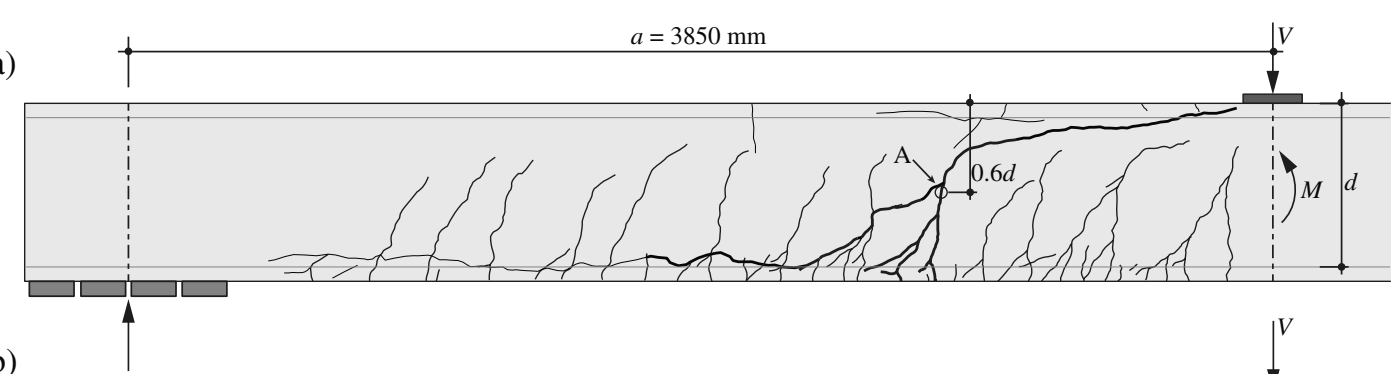

(b)

(c)

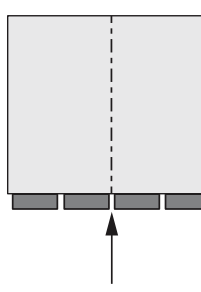

(d)

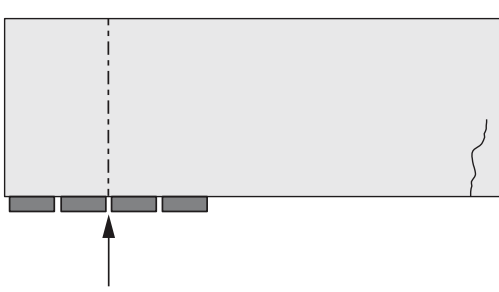

(e)
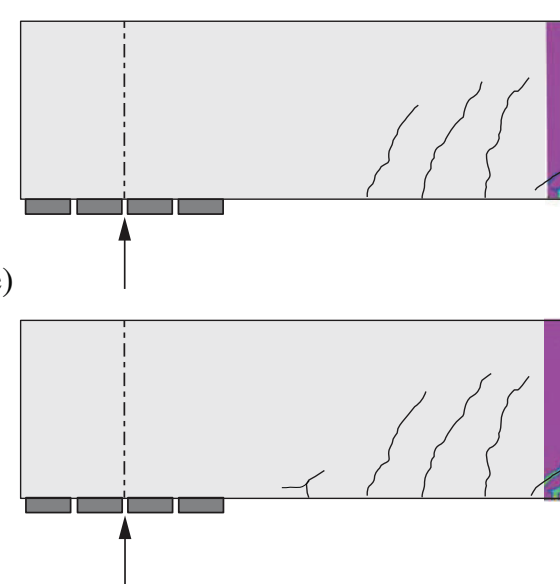
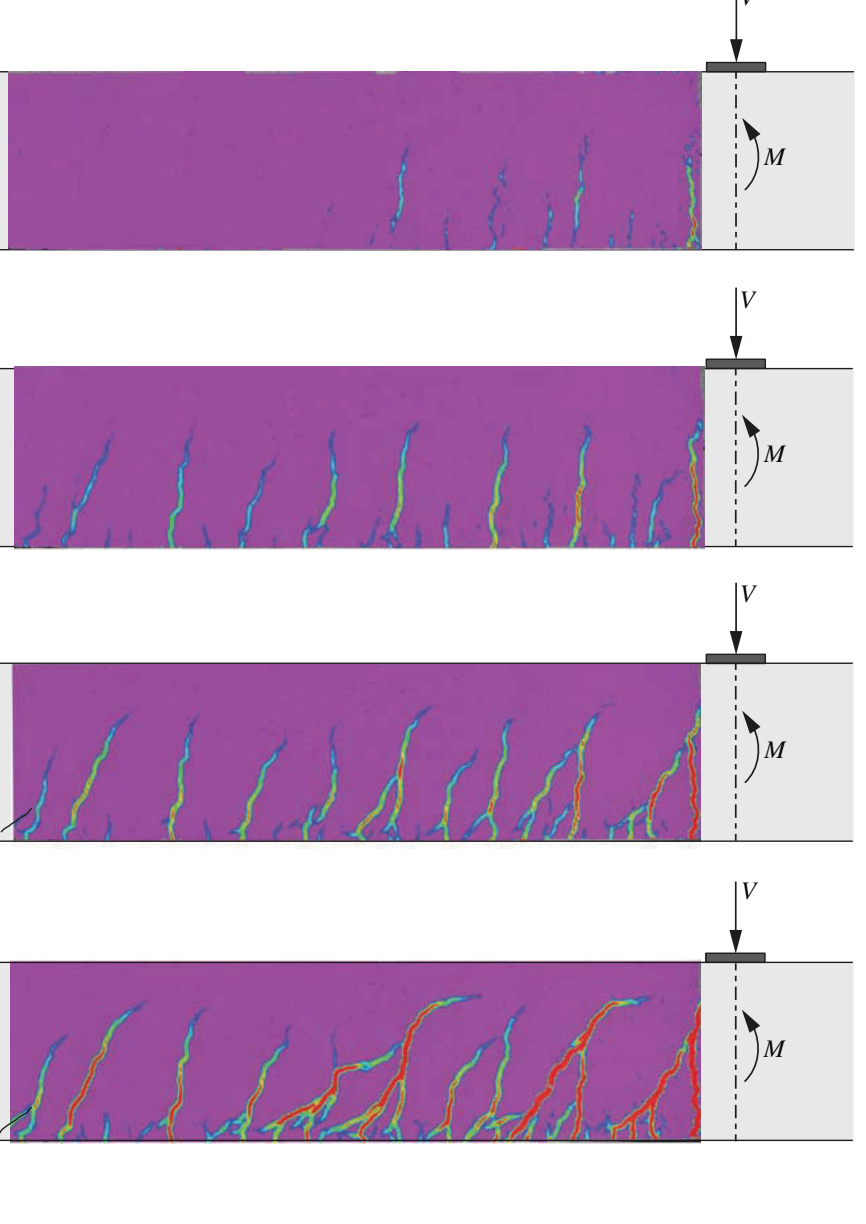
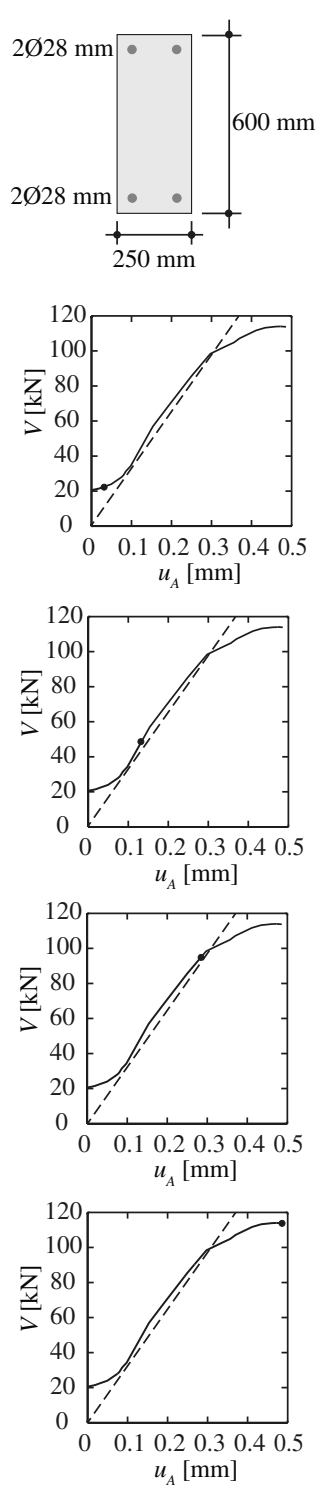

FIGURE 2 Analysis of the response of a simply supported beam: (a) geometry, support and loading conditions of specimen SC70; and horizontal crack opening at point A (uA) for: (b) an early cracking stage; (c) stabilized cracking and development of type D cracks; (d) near failure; and (e) failure 
(a)

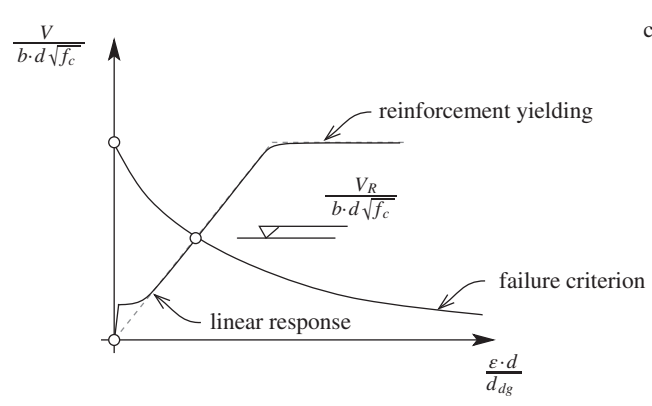

(c)

$$
\log \left(\frac{V_{R}}{b \cdot d \sqrt{f_{c}}}\right)
$$

FIGURE 3 Size effect in shear failures: (a) failure criterion, flexural behavior and failure load according to the critical shear crack theory (CSCT); (b) control section and reference strain; and (c) size-effect law according to the CSCT and comparison to the database of Reference 5 (b)

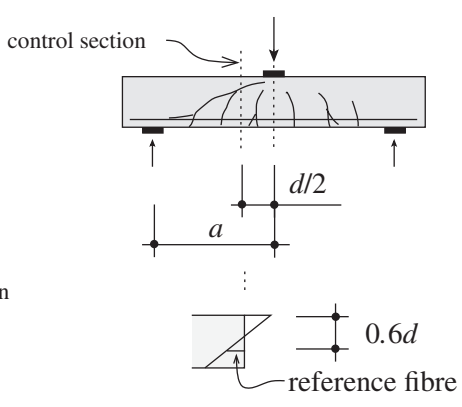

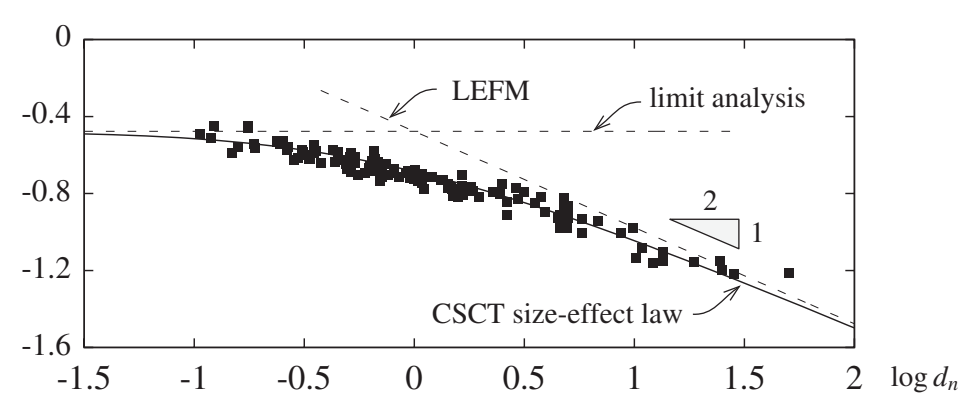

where $\rho$ refers to the reinforcement ratio, $E_{s}$ to the modulus of elasticity of the reinforcement, and $c$ refers to the depth of the compression zone ${ }^{5}$ :

$$
c=\rho \cdot d \frac{E_{s}}{E_{c}}\left(\sqrt{1+\frac{2 E_{c}}{\rho \cdot E_{S}}}-1\right),
$$

and with $E_{c}$ referring to the modulus of elasticity of concrete.

By introducing the value of $\varepsilon$ of Equation (2) into Equation (1), the shear resistance $\left(V_{R}\right)$ can be determined, which results in the following expression ${ }^{7}$ :

$$
\frac{V_{R}}{b \cdot d \sqrt{f_{c}}}=\frac{-1+\sqrt{1+4 d_{n}}}{6 d_{n}},
$$

where $d_{n}$ is a parameter accounting for size and strain effects. ${ }^{7}$ It can be noted that this expression is consistent with the size-effect law for shear failures by Bažant. ${ }^{6}$ The validity of the expression can in fact be assessed by means of test results as most tests of beams in shear correspond to this support and loading conditions, see Figure $3 \mathrm{c}$. For failures governed by limit analysis $\left(d_{n} \rightarrow 0\right)$, no size effect is observed whereas for large sizes $\left(d_{n} \rightarrow \infty\right)$, the slope (in double-log scale) of the strength corresponds asymptotically to $-1 / 2$ in accordance with the LEFM (Figure 3c).

\section{3 | Size effect in shear for redundant members}

Despite the fact that the majority of shear tests are performed in statically determinate members, actual structures where shear strength governs are in many cases redundant. Structural redundancy may be considered both in the transversal direction (Figure 1c) as well as in the longitudinal direction when concentrated loads are acting (Figure 1d). Due to structural redundancy, redistributions of internal shear forces are possible, which may deviate the relationship between the acting shear force and the crack openings at the shear-critical region from a linear one.

The response of a redundant structure is for instance shown in Figure 4. It corresponds to a continuous one-way slab subjected to distributed loading, where the response of such element is investigated at $d / 2$ (control section) from the support region (Figure 4a). Some phases can be differentiated, corresponding first to an uncracked behavior, followed by cracking near the support, cracking at mid-span and eventually yielding of the reinforcement of both regions. The evolution of the bending moments at mid-span and support (Figure $4 \mathrm{~b}$ ) shows that the response is not linear, deviating due to cracking and yielding occurring at different load levels at mid-span and support. This influences the response of the element in terms of the shear force-tocrack opening relationship, leading to a nonlinear behavior. The shear strength can be determined by calculating the reference strain by means of Equation (2) and by accounting for the actual values of the bending moment and shear force (Figure 4b). In so doing, a nonlinear response is obtained with a stiffer behavior than that corresponding to a linear prediction (two calculated cases are shown in Figure 4c). If such analysis is performed for geometrically identical members but scaled, one can derive the size-effect law. Two cases are for instance presented in Figure 4d, one corresponding to a moderate flexural reinforcement ratio $\left(\rho_{\text {hog }}=\right.$ $0.5 \%)$ and another to a high flexural reinforcement ratio 
(a)

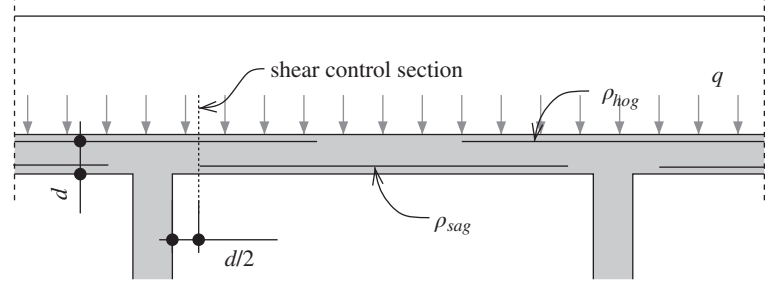

(c)

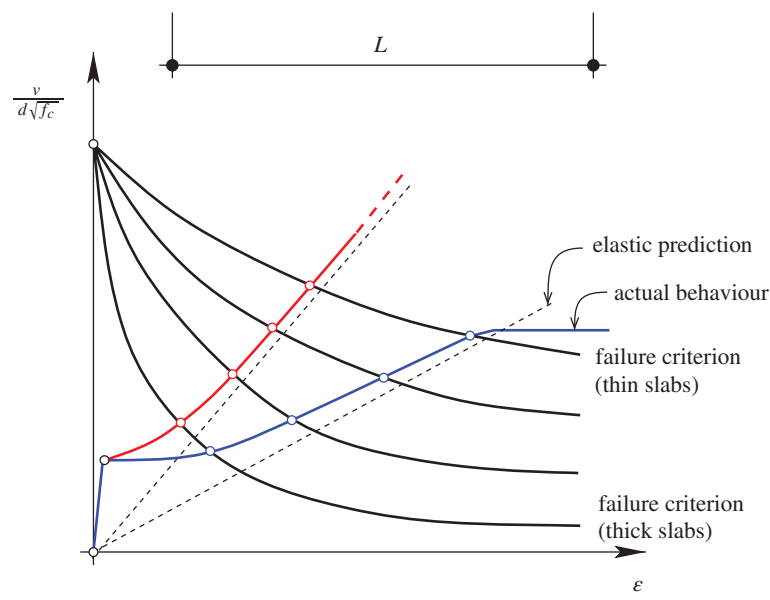

(b)

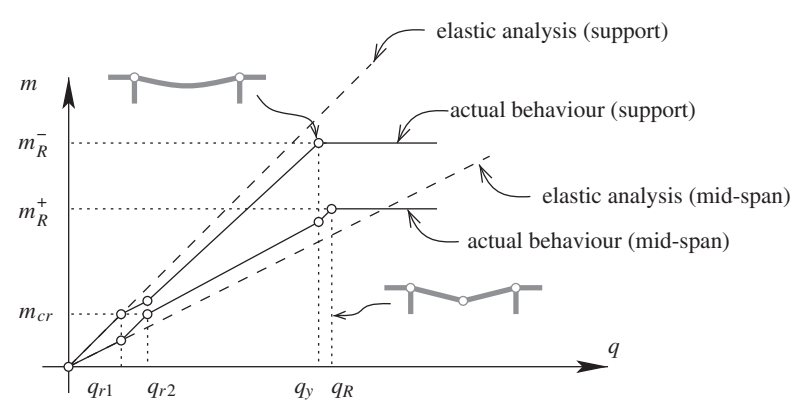

(d)

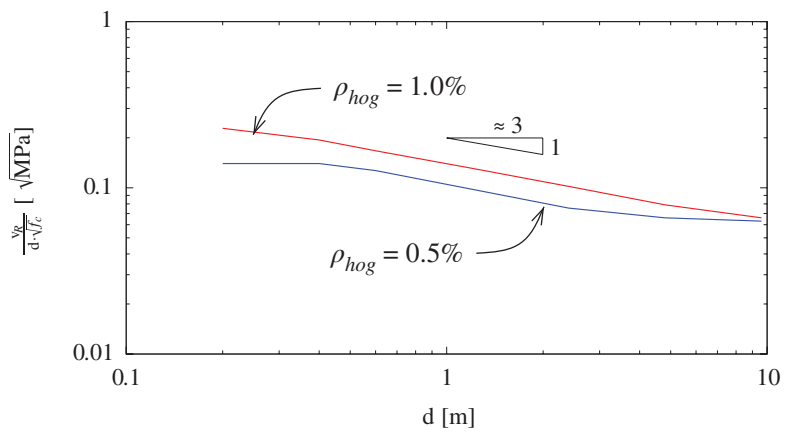

FIGURE 4 Influence of size effect on a redundant member: (a) case investigated; (b) evolution of bending moments on the support and mid-span sections; (c) load-reference strain response; and (d) calculated size effect as a function of the flexural reinforcement ratio plotted in double-log scale (red curve: $\rho$ hog $=1 \%$, $\rho$ sag $=0.5 \%$; blue curve: $\rho$ hog $=0.5 \%, \rho$ sag $=0.3 \%$ )

$\left(\rho_{\text {hog }}=1.0 \%\right)$. From Figure $4 \mathrm{~d}$, one can observe that the slope of the size-effect law tends to zero for low sizes (governed by the strength criterion) and that for large size members it tends to a value of approximately $-1 / 3$. This latter slope is milder than that predicted by LEFM $(-1 / 2)$ due to the nonlinear response exhibited by the members. The fact that the slope is milder than that of LEFM indicates that the assumption on the linear behavior for a redundant structure deviates from its actual behavior and leads to safe predictions in terms of the shear strength.

A similar consideration can be performed with respect to structures that are redundant in the transversal direction (due to a two-way slab behavior, refer for instance to the deck slab subjected to a concentrated action shown in Figure 1d). Detailed measurements performed by Natário et $\mathrm{al}^{17}$ have shown that strong redistributions in the bending and shear fields occur in the region where shear failure occurs, with load being transferred to less cracked regions. Also, crack openings are shown to have a highly nonlinear response due to the progression of the critical shear crack up to failure. These observations show that the structural redundancy due to a two-way slab behavior is also a potential source of loss of linear response and shall thus mitigate size-effect influence (corresponding to milder slopes of the size-effect law for large sizes). More details on the behavior of two-way slabs will be presented in the following section with reference to the punching shear strength of slab-column connections.

\section{I SIZE AND STRAIN EFFECTS IN PUNCHING FAILURES OF SLAB-COLUMN CONNECTIONS}

\section{1 | Nonlinear response of two-way slabs and shear strength}

The CSCT can also be used as a consistent frame for investigating the punching shear strength of two-way slabs. ${ }^{9}$ With reference to the opening of the critical shear crack, it is assumed to be correlated to the slab rotation ( $\psi$, see Figure $5 b$ ) times the effective depth of the member: $w \propto \psi \cdot d$. This term accounts again for both the size and strain level of the member. Similarly to the shear strength of one-way slabs, the failure criterion can be described according to Muttoni $^{9}$ by a hyperbolic relationship:

$$
\frac{V_{R}}{b_{0} \cdot d \sqrt{f_{c}}}=\frac{3 / 4}{1+15 \frac{\psi \cdot d}{d_{d g}}}(\text { SI units }[\mathrm{MPa}, \mathrm{mm}])
$$

where $b_{0}$ refers to the length of the control perimeter (located at $d / 2$ of the edge of the supported area). As for shear failures, the shear strength decreases for increasing crack openings (or decreasing crack roughness $d_{d g}$ ).

The shear strength is calculated (in a similar manner as for shear failures) by intersecting the punching failure criterion with the load-rotation response of the slab. With respect to the latter, the behavior is markedly nonlinear due to the 
(a)

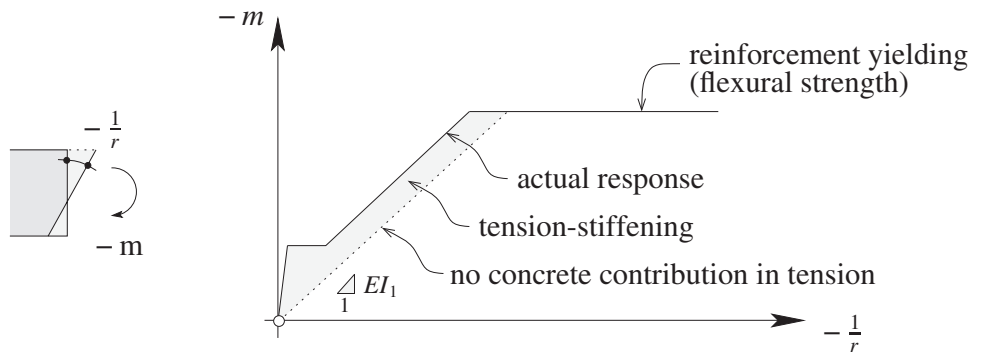

FIGURE 5 Realistic behavior of a slab: (a) moment $(m)$-curvature $(1 / r)$ diagram of a slab element with tension-stiffening effects; and (b) load-rotation relationship of a slab-column connection with different regimes (calculated assuming a quadri-linear moment-curvature diagram $^{9}$ ) (b)
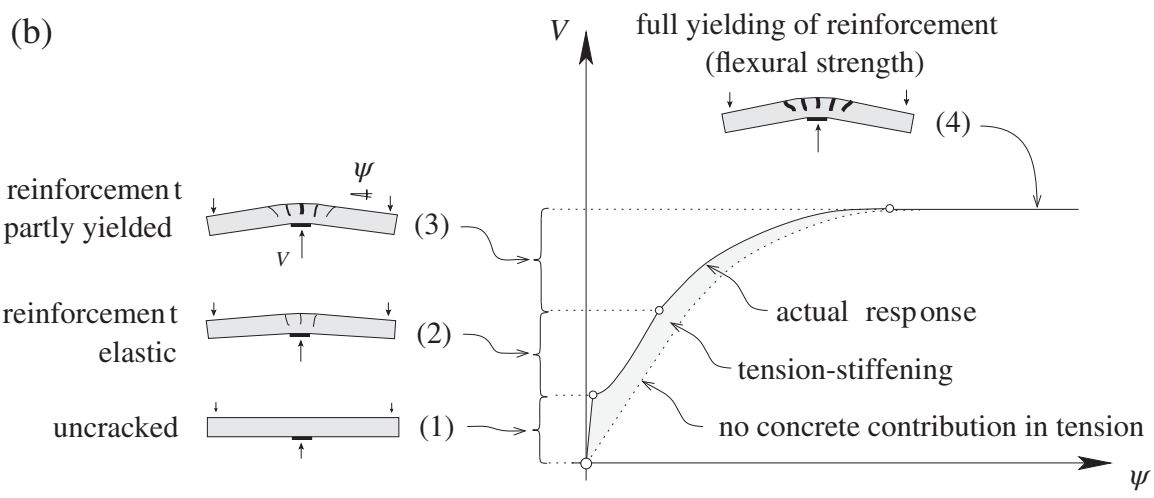

distribution of bending moments in the slab (in the radial and tangential directions ${ }^{9}$ ) as well as to the moment-curvature response of a reinforced concrete section (simplified as a quadri-linear response in Figure 5a).

A detailed analysis and derivation of the load-rotation response of slab-column connections has been thoroughly presented by Muttoni ${ }^{9}$ (extended considerations accounting for the continuity of flat slabs have also been developed by Einpaul et $\mathrm{al}^{8,18}$ ). According to these works, the loadrotation relationship (Figure 5b) comprises a number of regimes:

- First, the slab behaves in an uncracked regime (linearelastic regime (1) in Figure 5b)

- Second, cracking develops in the member with all reinforcements in the elastic regime ((2) in Figure 5b).

- Third, local yielding of the reinforcement occurs in the vicinity of the column ((3) in Figure 5b) but still a part of the reinforcement remains elastic.

- Fourth, all reinforcement is yielded, and the slab eventually reaches the flexural strength ((4) in Figure 5b)

The complete load-rotation curve describing the response of the member can be observed to be highly nonlinear, with a progressive loss of stiffness as load increases. The response is in fact to a large extent controlled by tension-stiffening effects. In the radial direction, tension stiffening can near failure be reduced due to a delamination crack as for one-way slabs. Nevertheless, in the tangential direction, tension stiffening is very relevant as it affects the whole slab surface and develops until failure. In actual (continuous) flat slabs, the response of the member (characterized by its load-rotation curve) is also influenced by the reinforcement at mid-span and the moment redistributions that occur. ${ }^{8,18}$

The significance of the tension-stiffening effects can be observed in Figure 6 with reference to two tests performed by Guandalini et $\mathrm{al}^{19}$ on geometrically identical specimens scaled approximately 1:2. Although both specimens failed in punching, the smaller exhibited a behavior with a significantly larger deformation capacity, failing in regime (3) (almost beginning of regime (4)). The thicker specimen, however, showed a rather brittle behavior and failed in the transition between regimes (2) and (3). Both specimens

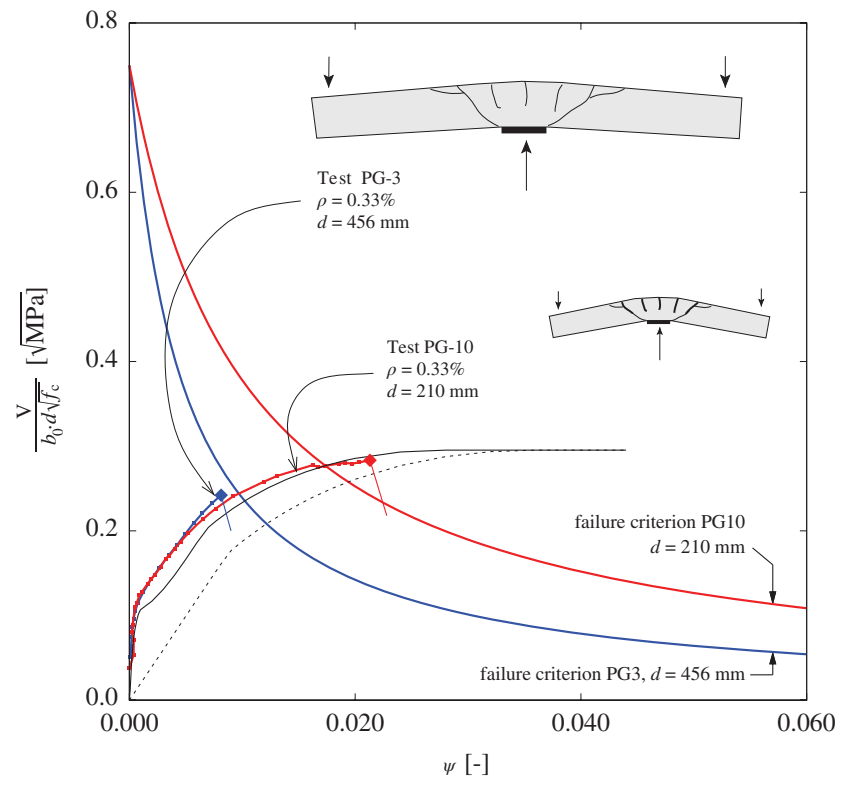

FIGURE 6 Experimental response of thick and thin slabs for geometrically scaled specimens (tests PG-3 and PG-10 from Reference 19) and comparison to predicted flexural behavior and failure criterion 
showed a markedly nonlinear behavior and their response was characterized by the tension-stiffening effects, closely following the theoretical prediction described in Reference 9 (refer to Figure 6). It is also interesting to observe that the size effect does not only influence the strength and deformation capacity, but even the failure mode.

As a consequence of the nonlinear behavior of slabs, it can be stated that the size effect cannot be described for large specimen sizes by the LEFM (as for simply supported beams without transverse reinforcement failing in shear). For these cases, the dependence of the strength with respect to the size cannot correspond to a slope $-1 / 2$ (in double-log scale), but shall be milder (see also the next section).

\subsection{Size effect in punching failures according to the CSCT}

The CSCT can be used as previously explained in order to predict the influence of size on the punching shear strength. For instance, Figure $7 \mathrm{a}$ plots the predictions of this theory compared to the experimental programme of Guandalini et $\mathrm{al}^{19}$ (geometrically identical specimens but scaled with $d=100 \div 456 \mathrm{~mm}$ ). The influence of size effect is observed to be variable consistently with the size-effect law. For low sizes, the size-effect influence is limited as the behavior is mostly controlled by the strength criterion. For large specimen sizes, the influence of size becomes more significant. With respect to the slope, the tension-stiffening effects and the nonlinearity of the load-rotation relationship do not yield to the asymptotic slope predicted by LEFM $(-1 / 2$ in double-log scale) but to a milder value (approximately $-1 / 3$ in double-log scale), refer to Figure 7a. The slope depends in addition on the amount of flexural reinforcement, as this parameter influences the plastic deformations at failure and different regimes of the load-rotation curve may govern (refer to Figure 5b).

The significant role of tension stiffening in this response can be observed in Figure 7b, where the size effect is calculated assuming no contribution of concrete in tension leading thus to a linear response of the slab before yielding of the reinforcement. In this case, the slope is steeper, corresponding (exactly) to $-1 / 2$ in agreement to the LEFM prediction (the mathematical derivation of this value can be consulted elsewhere ${ }^{14}$ ). This confirms that the CSCT is consistent to LEFM provided that the response of the member is linear. However, as previously shown (refer to Figure 6 for instance), the actual behavior of two-way slabs is not linear and thus the size-effect influence has to be milder than that of LEFM.

The value $-1 / 3$ obtained for the influence of size in punching failures is interestingly similar to the one previously calculated for redundant one-way slabs, showing the significance of the structural response and tension stiffening on this phenomenon.

\section{4 | IMPLICATIONS FOR DESIGN- APPROACH OF FIB MC2010}

fib MC2010 ${ }^{3}$ punching shear provisions are based on the $\mathrm{CSCT}^{13}$ by incorporating the so-called levels-ofapproximation (LoA) approach. ${ }^{20}$ To that aim, a simplified load-rotation relationship is used (based on a number of assumptions justified in Reference ${ }^{13}$ ) leading to the following expression:

$$
\psi=1.5 \frac{r_{s}}{d} \frac{f_{y}}{E_{s}}\left(\frac{m_{s}}{m_{R}}\right)^{3 / 2}
$$

where $r_{s}$ refers to the distance from the center of the column to the line of contraflexure of bending moments, $f_{y}$ to the yield strength of the reinforcement, $E_{s}$ to its modulus of elasticity, $m_{s}$ to the average bending moment acting in the support strip of the slab, and $m_{R}$ to the average flexural strength in the support strip of the slab.

The parabola of Equation (7) approximates with a single expression the nonlinear response of an actual slab (see Figure 7c-right) enhancing the easiness of use of the approach. The coefficients of the failure criterion (Equation (6)) are also slightly adapted to account for the scatter of test results ${ }^{13}$ and in order to provide a suitable level of safety for design.

Design can be performed following various LoA to estimate the punching strength of a slab-column connection. This allows performing simple and safe designs for noncritical members, but the accuracy can be refined upon necessity by a more accurate evaluation of the physical parameters implied.

The most simple LoA proposed in MC2010 (LoA I) is aimed at verifying the dimensions of the slab-column connection. This LoA assumes yielding of the flexural reinforcement prior to punching $\left(m_{s}=m_{R}\right)$ so to ensure a ductile behavior of the connection. Additionally, this consideration provides a safe estimate of the actual strength (as connections may be over-reinforced in bending to increase their punching strength).

For LoA II and higher, the value of $m_{s}$ is to be calculated as a function of the acting shear force. This allows determining the punching strength in case the reinforcement in the support strip is not fully yielded and thus accounting for the potential gain in punching strength when flexural reinforcement is not fully yielded (corresponding to lower crack widths). Figure $7 \mathrm{c}$ plots the predicted punching strength by using LoA II for the same cases as previously investigated with the CSCT (Figure 7a). The calculated size effect is observed similar to the one derived from the CSCT accounting for a more realistic load-rotation relationship (Figure 7a), with an slope in double-log scale of approximately $-1 / 3$ for large members (asymptotic value of -1 / 2.5). This slope is again milder than that of LEFM and consistent with the detailed approach of the CSCT. 
(a)
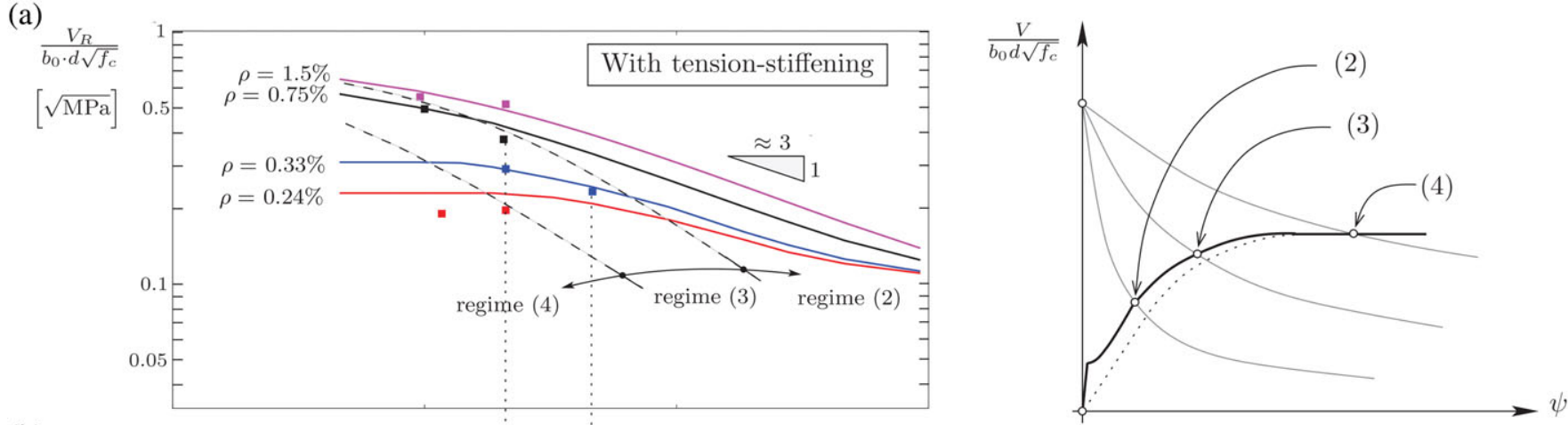

(b)
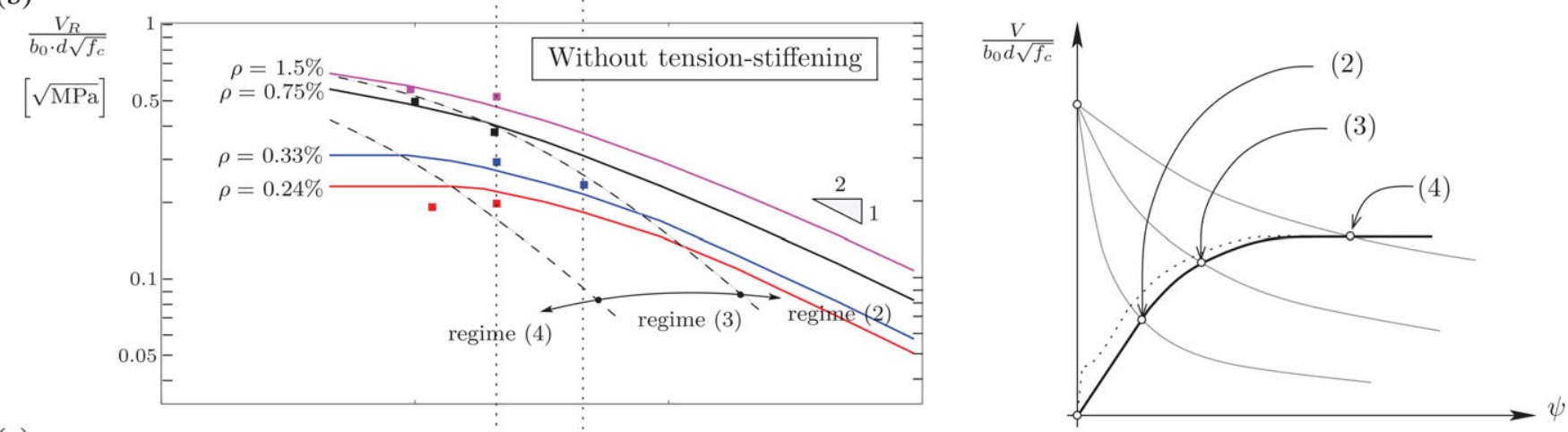

(c)
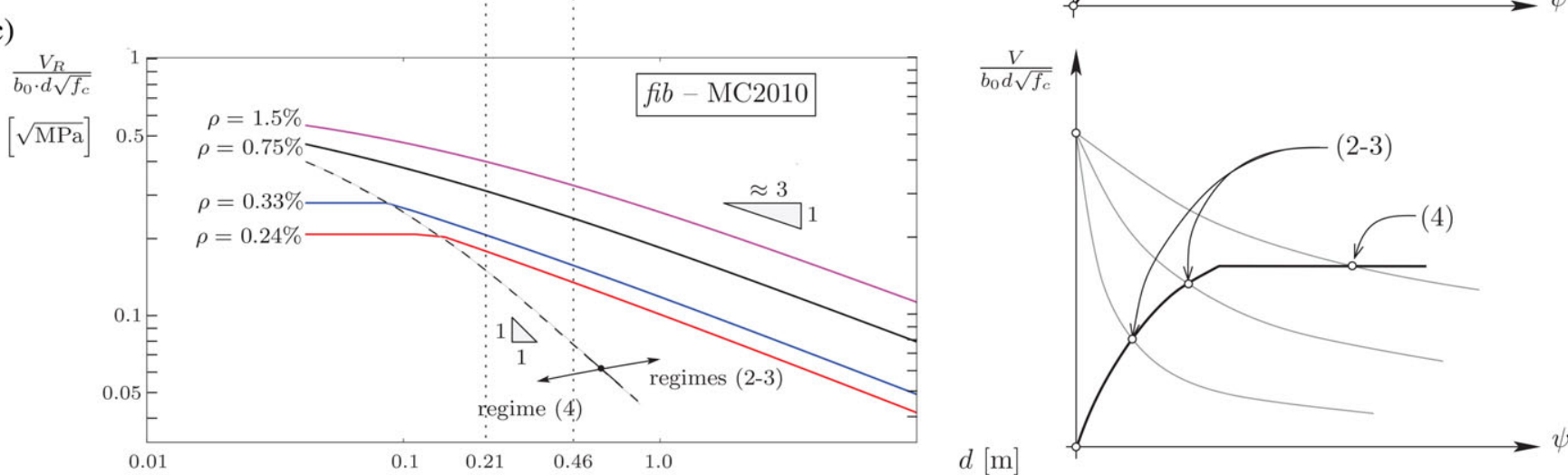

FIGURE 7 Predicted size effect by the critical shear crack theory (CSCT) and comparison to the test series presented in Reference 19 plotted in double-log scale (tests PG-2b and PG-9 for $\rho=0.24 \%$; tests PG-3 and PG-10 for $\rho=0.33 \%$, tests PG-7 and PG-19 for $\rho=0.75 \%$ and PG-1 and PG-6 for $\rho=1.50 \%$ ): (a) accounting for tension-stiffening effects; (b) without consideration of tension-stiffening effects; and (c) according to fib MC2010

It is also interesting to observe that in Figure $7 \mathrm{c}$, a dashed line is plotted indicating the condition at which all flexural reinforcement yields at punching failure (regime (4) governing). This dashed line represents actually the condition of LoA I, as slabs designed complying with LoA I ensure reaching their flexural capacity before failing in punching. Size effect is much stronger in this case (slope $-1 / 1$ ) as, for increasing sizes, the nominal punching shear strength decreases (refer for instance to Figure 6) and thus to ensure full yielding of the flexural reinforcement the reinforcement ratio of the slab shall be reduced accordingly. Consequently, slabs designed using LoA I cannot be investigated for a size effect, but for the influence of size on the transition from failures governed by the shear capacity to failures governed by bending capacity (as not only the size but also the flexural reinforcement ratio varies, and they present a combined size and strain effect).

\section{5 | CONCLUSIONS}

This paper investigates the influence of size effect for failures in shear and punching shear. The investigation highlights the differences between statically determinate and redundant members, accounting for the loss of linearity between the acting shear force and crack widths in the latter. Its main conclusions are summarized below:

1. The significance of size effect depends not only upon the size of the member (low significance for low sizes and high significance for large sizes), but also on the capacity of a structure to redistribute internal forces due to cracking and reinforcement yielding.

2. Classical tests on statically determinate beams provide a size-effect influence consistent to LEFM for asymptotically large sizes (slope of $-1 / 2$ in double-log scale). 
However, size effect shall deviate from LEFM in actual (mostly redundant) structures as the shear action and shear resistance (proportional to crack widths and thus to bending moments) are no longer proportional.

3. It has been observed experimentally that size effect in punching of slab-column connections (which are internally redundant members) is milder than that predicted by LEFM. This is in agreement to the previous consideration and can be theoretically explained by the CSCT.

4. According to the CSCT, the predicted size-effect slope for redundant members is closer to $-1 / 3$ (instead of -1 / 2). This indicates that design on the basis of size-effect factors calibrated for shear failures in statically determinate members may be too safe for actual structures.

5. fib MC2010 design provisions for punching already account for a nonlinear behavior in the flexural response of a slab and the resulting slope for the size effect (in double-log scale) is similar to $-1 / 3$, in consistency with the CSCT and the previous theoretical considerations.

\section{ACKNOWLEDGMENTS}

This work was supported by the Swiss Federal Road Administration (research grant AGB 2011-015 "Shear strength of slabs and cut-and-cover tunnels")

\section{NOTATION}

$E_{C}$ MODULUS OF ELASTICITY OF CONCRETE

$E_{s} \quad$ modulus of elasticity of reinforcement

$E I_{1} \quad$ uncracked flexural stiffness

$M$ bending moment

$V \quad$ shear force

$V_{R} \quad$ shear strength

$a$ shear span

$b \quad$ width of beam

$b_{0} \quad$ control perimeter length

$c$ thickness of compression zone

$d$ effective depth (distance from the centroid of the flexural reinforcement to the outermost compressed fiber)

$\tilde{d} \quad$ normalized effective depth

$d_{d g} \quad$ equivalent crack roughness

$d_{g} \quad$ maximum aggregate size

$d_{n} \quad$ dimension parameter

$f_{c} \quad$ concrete compressive strength measured in cylinder

$f_{y} \quad$ yield strength of the reinforcement steel

$m \quad$ unitary bending moment

$m_{c r} \quad$ unitary bending moment at cracking

$m_{s} \quad$ average bending moment in the support strip of a slab

$m_{R} \quad$ average flexural strength in the support strip of a slab

$\tilde{v} \quad$ normalized shear force

$q$ distributed load

$r \quad$ radius of curvature $r_{s} \quad$ distance from center of column to the line of contraflexure of bending moments

$u_{A} \quad$ horizontal opening of crack at point $\mathrm{A}$

$v \quad$ unitary shear force

$w \quad$ crack width

$\varepsilon \quad$ reference strain

$\rho \quad$ reinforcement ratio

$\psi$ rotation

\section{REFERENCES}

1. American Concrete Institute Committee 318. Building Code Requirements for Structural Concrete ACI 318-14. Farmington Hills, MI: American Concrete Institute; 2014:519.

2. CEN European Committee for Standardization. Eurocode 2. Design of Concrete Structures-General Rules and Rules for Buildings, EN 1992-1-1. Brussels, Belgium; 2004:225.

3. Fédération internationale du béton. fib Model Code for Concrete Structures 2010. Germany: Ernst \& Sohn; 2013:434.

4. Collins MP, Bentz EC, Quach PT, Proestos GT. The challenge of predicting the shear strength of very thick slabs. Concr Int. 2015;37(11):29-37.

5. Muttoni A, Fernández Ruiz M. Shear strength of members without transverse reinforcement as function of critical shear crack width. ACI Struct J. 2008;105(2):163-172.

6. Bažant ZP, Kim J-K. Size effect in shear failure of longitudinally reinforced beams. ACI J Proc. 1984;81(5):456-468.

7. Fernández Ruiz M, Muttoni A, Sagaseta J. Shear strength of concrete members without transverse reinforcement: a mechanical approach to consistently account for size and strain effects. Eng Struct. 2015;99:360-372.

8. Einpaul J, Fernández Ruiz M, Muttoni A. Influence of moment redistribution and compressive membrane action on punching strength of flat slabs. Eng Struct. 2015;86:43-57.

9. Muttoni A. Punching shear strength of reinforced concrete slabs without transverse reinforcement. ACI Struct J. 2008;105(4):440-450.

10. Dönmez A, Bažant ZP. Size Effect on Punching Shear Strength of Reinforced Concrete Slabs Without and With Shear Reinforcement, Report No. 15-12/936s, Department of Civil and Environmental Engineering, Northwestern University, IL; 2016, 23.

11. Muttoni A, Fernández Ruiz M. The critical shear crack theory for punching design: from a mechanical model to closed-form design expressions, Joint ACI-fib International Symposium "Punching Shear of Structural Concrete Slabs", Philadelphia, PA, October 23-27, 2016.

12. Muttoni A, Fernández Ruiz M. MC2010: the critical shear crack theory as a mechanical model for punching shear design and its application to code provisions. In: fib Federation for Structural Concrete, Bulletin 57; 2010:31-60

13. Muttoni A, Fernández Ruiz M, Bentz E, Foster SJ, Sigrist V. Background to the Model Code 2010 shear provisions-part II punching shear. Struct Concr. 2013;14(3):195-203.

14. Fernández Ruiz M, Muttoni A. Size effect on punching shear strength: differences and analogies with shear in one-way slabs. In: fib Federation for Structural Concrete, Bulletin 81; 2017:59-72.

15. Broms CE. Tangential strain theory for punching failure of flat slabs. $A C I$ Struct J. 2016;113(1):95-104.

16. Cavagnis F, Fernández Ruiz M, Muttoni A. Shear failures in reinforced concrete members without transverse reinforcement: a critical analysis on the basis of test results. Eng Struct. 2015;103:157-173.

17. Natário F, Fernández Ruiz M, Muttoni A. Shear strength of RC slabs under concentrated loads near linear supports. Eng Struct. 2014;76:10-23.

18. Einpaul J, Ospina CE, Fernández Ruiz M, Muttoni A. Punching shear capacity of continuous slabs. ACI Struct J. 2016;113(4):861-872.

19. Guandalini S, Burdet O, Muttoni A. Punching tests of slabs with low reinforcement ratios. ACI Struct J. 2009;106(1):87-95.

20. Muttoni A, Fernández Ruiz M. The levels-of-approximation approach in MC 2010: applications to punching shear provisions. Struct Concr. 2012;13(1):32-41 


\section{AUTHOR'S BIOGRAPHIES}

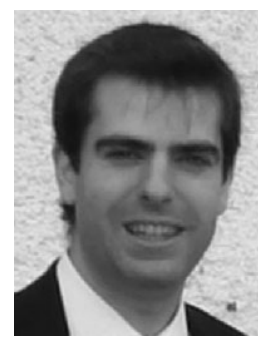

Miguel Fernández Ruiz PhD

Senior Lecturer

École Polytechnique Fédérale de

Lausanne

Station 18, CH-1015 Lausanne

Switzerland

miguel.fernandezruiz@epfl.ch

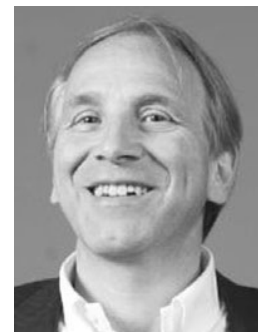

Aurelio Muttoni PhD,

Professor

École Polytechnique Fédérale de Lausanne

Station 18, CH-1015 Lausanne

Switzerland aurelio.muttoni@epfl.ch
How to cite this article: Fernández Ruiz M, Muttoni A. Size effect in shear and punching shear failures of concrete members without transverse reinforcement: Differences between statically determinate members and redundant structures. Structural Concrete. 2017;1-11. https://doi.org/10.1002/suco.201700059 